\title{
CLÁSSICOS LITERÁRIOS COMO MOTIVAÇÃO PARA A AULA DE FILOSOFIA
}

\author{
LITERARY CLASSICS AS A MOTIVATION FOR THE CLASS OF PHILOSOPHY
}

Michael de Oliveira'

Resumo: O presente trabalho pretende referenciar o ensino de Filosofia desde textos da literatura clássica, abordando, especificamente, a obra "As Viagens de Gulliver", de Jonathan Swift, apresentando que não existe apenas uma leitura agradável em obras clássicas. O autor aborda problemas éticos e políticos de seu tempo tendo em consideração o contexto vivido, onde duas grandes potências, Inglaterra e França, disputavam a soberania mundial, com suas revoluções e inovações tecnológicas. O texto traz uma crítica, apontando questões políticas que fizeram com que os reinos de Lilipute e Blefuscu se apartassem por questões miúdas. Aborda contextos éticos e morais destacando problemas com corrupção. Apresenta situações de um governo patrimonialista além de apresentar certo nível de racionalismo crítico. A imagem deturpada da humanidade é ponto de destaque, percebendo-se aspectos totalitários denunciados em uma das viagens. $\bigcirc$ objetivo deste trabalho é propor a utilização da obra, bem como de outras obras literárias, para verificar contexto histórico, ético e político, que passam despercebidos da maioria dos estudantes. Percebe-se, na obra referida, contexto atemporal. Surge o desafio de averiguação acerca da questão ético/política ainda em destaque, com diversas questões, tais como: Quais as diferenças e/ou semelhanças que percebemos com esta questão atualmente? Por qual motivo Swift se utiliza desta fantasiosa imaginação em seu escrito? O que ele pretendia denunciar ou apurar?

Palavras-chave: Filosofia; Literatura; Clássico; Ética; Moral.

Abstract: The present work intends to reference the teaching of Philosophy from texts of classical literature, addressing, specifically, the book "Gulliver's travels" by Jonathan Swift, showing that there is not only an enjoyable reading in classical works. The author discusses ethical and political problems of your time taking into account the context, where two great powers, England and France, vied for world sovereignty with their revolutions and technological innovations. The text brings a critical, pointing out political issues that caused the kingdoms of Lilliput and 
Blefuscu get sidetracked by small problems. Addresses ethical and moral contexts, highlighting problems with corruption. Presents a patrimonial Government situations in addition to presenting certain level of critical rationalism. The distorted image of humanity is the highlight, realizing totalitarian aspects reported on one of the trips. The aim of this work is to propose the use of the book, as well as other literary works, for check the historical context, ethical and political, that go unnoticed to most students. One realizes, on literary work, timeless context. The challenge of finding out about the ethical / political question still highlighted, with several questions, such as: what are the differences and/or similarities we perceive with this matter today? Why Swift uses this fanciful imagination in your writing? What he intended to denounce or investigate?

Keywords: Philosophy; Literature; Classic; Ethic; Moral.

\section{INTRODUÇÃO}

Enquanto educadores, nós sempre procuramos desenvolver metodologias de estudo que possam conter a atenção dos alunos, entretanto, no mundo digital que vivenciamos atualmente, se torna uma tarefa árdua, difícil de ser desenvolvida, pois, jovens e adolescentes possuem o mundo todo em apenas um toque em uma tela, ou uma linha de palavras-chave em determinado site. Para tanto é necessário criar alternativas a utilizar em sala de aula, conforme expõe Ramos, Gutierres e Kich:

Há uma necessidade vigente da educação para o pensar - nós, professores, buscamos criar alternativas pedagógicas que estimulem a habilidade de pensar e de resolver problemas, capacidade que pode ser incrementada pelo estudo da literatura e da filosofia: a primeira, pelas múltiplas experiências proporcionadas pelos personagens do texto ficcional e das vivências do leitor, considerando suas interpretações pessoais e sua individualidade como ser; e a segunda, pelo rigor de pensamento que impõe a busca de "verdades" provisórias da ciência. Sob este ponto de vista, a filosofia e a literatura desempenham papéis fundamentais na formação para o raciocínio, cooperando para a busca de soluções para problemas da humanidade e capacitando o homem a pensar e a agir de forma autônoma. (RAMOS, GUTIERRES, KICH, 2011, p. 319).

Então como podemos experienciar, ou tornar possível a experiência do desenvolvimento de uma metodologia eficaz para aulas de filosofia no ensino médio que seja atrativa, agradável e que nos possibilite o desfrute de resultados eficazes sem que, necessariamente, tenhamos que utilizar de ferramentas digitais, mas sim com a utilização da maior das ferramentas criadas pelo homem, a saber, a escrita e a leitura, mas sem perder a aprendizagem de filosofia de vista? Tal fato se torna desafiador na medida em que se percebe que jovens e adolescentes gradativamente "consomem" menos a literatura, preocupam-se menos em tornar hábito à leitura, especialmente quando pensamos em literatura clássica.

Temos sempre que levar em consideração que na leitura devem ser observados dois aspectos, ou, em outras palavras, duas funções, como assim denomina Cossutta, a saber: a função didática e a função pedagógica. 
A primeira é a função didática: o filósofo procura provocar a compreensão, explica, explicita, antecipa-se às incompreensões do leitor. [...] A segunda função supõe sempre a primeira, mas o inverso nem sempre é verdadeiro: trata-se da função pedagógica, que visa a transformação do pensamento e se estende a tudo o que torna possível a conversão do leitor. (COSSUTTA, 1994, p.29).

Portanto, faz-se necessária uma abordagem mais incisiva diante de tal dificuldade, especialmente no momento em que tentamos utilizar a literatura clássica para o desenvolvimento de uma atividade filosófica, pois, para muitos, a filosofia apenas está presente no seu próprio gênero literário, reclusa a si mesma, que deveras é de difícil leitura para uma determinada faixa etária que, não por vontade própria, preza pelo imediatismo. Conectado a isso está a desatenção com a leitura, portanto torna-se necessário "aprender a ler", como bem apresenta Cossutta: "O conseIho mestre é formulado assim: 'É preciso aprender a ler', sem que nunca, no entanto, do colegial ao doutoramento, as regras de leitura sejam realmente explicitadas" (COSSUTTA, 1994, p.1). Fator apoiado e complementado por Ramos, Gutierres e Kich:

Tanto a literatura quanto a filosofia oportunizam aos leitores discussão acerca de ações que inerentes a vida. Tal postura não assume verdades, pelo contrário, questiona a realidade e busca respostas a diferentes perguntas.Textos clássicos, por exemplo, são um referencial que poderiam contribuir para a construção de um sujeito mais questionador, mais civilizado e, consequentemente, mais humano. (RAMOS, GUTIERRES, KICH, 2011, p.319).

Por tal consideração é que abordaremos uma possibilidade de utilização da literatura clássica de forma a convencer alunos e alunas de que podemos retirar conceitos filosóficos, ou ainda melhor, problemáticas filosóficas, de qualquer obra, especialmente quando temos em tela uma obra da envergadura de As Viagens de Gulliver, de Jonathan Swift².

A obra aborda diversos contextos e conceitos que podem ser explorados pelos professores como problemática relacionada à atualidade. Cossutta, apoiado ainda por Ramos, Gutierres e Kich, apresenta que existem diversas maneiras de perceber determinado texto como filosófico:

[...] parece que, apesar da diversidade dos gêneros, das teses, dos modos de exposição, pode-se apreender funções bastante gerais que determinam aquilo que torna um texto propriamente filosófico.

De fato, um leitor atento percebe intuitivamente que, para além de opções ideológicas, de tipos de texto (diálogo, tratado, resumo, carta) ou de contextos sociais e históricos, pode-se detectar fenômenos gerais. (COSSUTTA, 1994, p.5).

A filosofia e a literatura dialogam de diferentes formas, já que ambas abordam temas universais e oferecem oportunidades de reflexão para que o ser humano supere o senso comum e desenvolva uma consciência crítica e estética, que dê suporte a sua ação. Alguns autores já se

2 A sensibilização para a temática proposta neste trabalho surgiv enquanto sugestão do Prof. Dr. Carlos Augusto Sartori em atividade relativa à disciplina História, temas e problemas da filosofia: como ler os clássicos. 
debruçaram sobre o assunto apontando elos entre os saberes filosóficos e literários. (RAMOS, GUTIERRES, KICH, 2011, p.318).

\section{O QUE É UM TEXTO CLÁSSICO?}

Chamamos clássico um texto que tenha sua importância histórica e que, após diversos anos, continue a colocar sua mensagem para o leitor. Portanto, clássico é o texto que não contém prazo de validade, trazendo a cada nova leitura outras perspectivas intrigantes que continuem a desafiar o intelecto em busca de problematizações. No dizer de Ramos, Gutierres e Kich:

O que define um texto como clássico? Há de se distinguir uma conceituação mais generalista e outra de cunho mais pessoal. A primeira engloba aqueles textos que, independentemente da época na qual foram escritos ou publicados, sempre têm algo a dizer a seus leitores e, portanto, assumem um caráter universal; já a segunda, além de abranger os princípios da concepção anterior, abrange aquelas leituras que exercem algum tipo de influência particular, à medida que se tornam inesquecíveis para quem as lê. (RAMOS, GUTIERRES, KICH, 2011, p. 319).

Importante o destaque acerca da palavra clássico, que provém do latim classicus, ou seja, dizia respeito às classes mais altas da sociedade romana e, por comparação, indicava algo que tinha superioridade em relação a outro. Por isso diz-se clássica determinada obra que se sobreponha em relação a outras de origem semelhante e que contenha sua importância na comunidade leitora de todos os tempos.

No contexto filosófico temos diversas obras que podemos chamar de clássicos, desde os filósofos antigos, como Platão e Aristóteles (recordando que Sócrates não deixara escrita obra impressa) até a atualidade. Podemos citar como clássicos as obras: A República, Fedro, Teeteto, entre outros de Platão; Organon, Ética a Nicômaco, entre outros, de Aristóteles; Suma Teológica, de Tomás de Aquino; O Príncipe, de Maquiavel; Discurso do Método, de Descartes; Leviatã, de Hobbes; O Contrato Social, de Rousseau; Crítica da Razão Pura, de Kant; Fenomenologia do Espírito, de Hegel; O Capital, de Marx; O Anticristo e Assim falava Zaratustra, de Nietzsche; enfim... São diversos autores e quase que uma infinidade de obras filosóficas produzidas e que ainda contém seu valor, quer seja histórico, quer seja problemático.

No campo da literatura podemos destacar diversos clássicos que podem ser utilizados para o intento que neste estudo é apresentado, tais como: llíada, de Homero; Robinson Crusoé, de Daniel Defoe; Dom Quixote, de Miguel de Cervantes; O Primo Basílio, de Eça de Queirós; Moby Dick, de Herman Melville; Guerra e Paz, de Leon Tolstói, Memórias Póstumas de Brás Cubas, de Machado de Assis; enfim, existe enorme gama de título que se dispõe ao estudo.

\section{ENTRANDO NO MÉRITO: AS VIAGENS DE GULLIVER}

Faz-se premente o destaque acerca da forma interpretativa que devemos ler textos de cunho filosófico. Portanto, cada qual pode ser remetido à conclusões distintas, diversas e, também divergentes. Tal fato é de importante relevância, pois nos dá plena liberdade de averiguação e conclusão. No dizer de Cossutta: 
em negativo de um leitor em potencial. Eles the atribuem um estatuto que o leitor real aceita ou recusa, conforme o trabalho de convicção faça dele um discípulo, um observador distante ou um adversário. (COSSUTTA, 1994, p.12).

A obra As Viagens de Gulliver (SWIFT, 1950) torna-se um clássico exatamente pela sua atemporalidade. Nesta obra o autor, de maneira até mesmo lúdica, aborda problemas éticos e políticos de seu tempo. Interessante o friso acerca da primeira vez que um adolescente se debruça sobre tal obra, por conta desta ludicidade, por vezes (quase que geralmente), não consegue compreender o real desejo do autor (a denúncia), prefere, ou melhor, é conduzido, por conta de sua jovialidade, a ficar com a fantasia da obra a perceber as entrelinhas que o autor propõe, por óbvio é plenamente perdoável tendo em vista a imaturidade a que se acomete. Ainda assim destaca-se que a jovialidade do leitor não é regra única para a falta de compreensão do texto, pois qualquer adulto desatento pode sofrer do mesmo equívoco. Tendo em vista tal situação podemos perceber que ocorrem equívocos relacionados com a obra e não com a idade ou experiência do leitor. Ramos, Gutierres e Kich nos apresentam que a qualidade das experiências é o que torna a leitura de textos clássicos agradável e problematizantes:

A riqueza da leitura de textos clássicos da literatura e da filosofia reside na qualidade de experiências que ela proporciona. Tais experiências são essenciais para o ser humano, tendo em vista sua necessidade de mudança e adaptação ao meio e à sociedade. Enquanto a filosofia traz à tona problemáticas existenciais do ser humano, a literatura apresenta essas problemáticas simbolicamente através da ficção. As duas áreas são complementares à medida que representam a vida de quem as lê e atuam no pensamento e na constituição dos sujeitos. Há uma necessidade vigente da educação para o pensar - nós, professores, buscamos criar alternativas pedagógicas que estimulem a habilidade de pensar e de resolver problemas, capacidade que pode ser incrementada pelo estudo da literatura e da filosofia: a primeira, pelas múltiplas experiências proporcionadas pelos personagens do texto ficcional e das vivências do leitor, considerando suas interpretações pessoais e sua individualidade como ser; e a segunda, pelo rigor de pensamento que impõe a busca de "verdades" provisórias da ciência. Sob este ponto de vista, a filosofia e a literatura desempenham papéis fundamentais na formação para o raciocínio, cooperando para a busca de soluções para problemas da humanidade e capacitando o homem a pensar e a agir de forma autônoma. (RAMOS, GUTIERRES, KICH, 2011, p.319).

Para tanto é necessário que tenhamos ciência do contexto vivido pelo autor, onde duas grandes potências, a saber: Inglaterra (pátria do autor) e França, disputavam a soberania global, com suas revoluções e inovações tecnológicas. Portanto quando, na obra, lê-se Lilipute, poderia se ler tranquilamente Inglaterra, ao passo que quando se lê Blefuscu, poderíamos interpretar por França sem receio de erro. (SWIFT, 1950)

Referente a isso, torna-se interessante destacar que, salvo raros momentos, a história do mundo sempre esteve reservada a um dualismo, quase que em uma circunstância maniqueísta, onde uma potência requer para si o título de maior e outra potência renega tal fato conside- 
rando-se, ela mesma, a maior. Questões políticas envolvem tal concorrência. Tal fato é um ponto que pode ser amplamente abordado em uma problematização filosófica em sala de aula.

O autor critica sua própria pátria, pois aponta que questões políticas fizeram com que os reinos de Lilipute e Blefuscu se apartassem. Surge então uma crítica velada do autor, pois percebese que todas as desavenças aparentadas na disputa entre os dois reinos são regadas a questões miúdas, exemplificado pelo autor no fato de que rixas ocorrem até mesmo pela consideração do lado correto em que se deve quebrar um ovo. Tal fato gerou grande repercussão interna surgindo uma rusga difícil de ser superada entre ambos os reinos, considerando-se inimigos mortais.

Em toda a obra percebemos que Swift tenta abordar questões relacionadas com a ética. Exemplo de tal fato se apresenta no trecho em que conta o pós-vitória de Lilipute em combate, vitória esta conquistada com o apoio do personagem principal, Gulliver. O, até então, gentil Imperador mostra sua face ditatorial ao pensar em executar opositores presos, mesmo após perceber o trabalho e a presteza do personagem principal que, quisesse ele, poderia ter exterminado o império de Lilipute tendo em vista sua estatura descomunal, bem como sua força em relação aos habitantes do local, entretanto preferiu se sujeitar à subserviência ao que ele considerava gentil Imperador.

Podemos perceber que saltam aos olhos do leitor atento diversas abordagens problemáticas que podem ser trabalhadas e interpretadas de maneira filosófica. Utilizando a obra em tela podemos trabalhar interdisciplinarmente e utilizando-se de uma função dialógica, pois podemos perceber diversas posições filosóficas em todo o enredo. Cossutta chama isto de "jogo múltiplo de referências".

O texto, através de um jogo múltiplo de referências, tece uma rede mais ou menos densa de intertextualidade sobre a qual poderá se construir o que, a partir de Bakhtin, é denominada função dialógica [...] com efeito, se o texto, através da função dialógica, constrói sua abertura no campo plural das posições filosóficas, ele se fecha e se encerra no mesmo movimento, pois o sujeito enunciador na primeira pessoa que está no centro da perspectiva e assegura a preparação do que é assim integrado. (COSSUTTA, 1994, p.31).

Aderindo à metodologia Cossuttariana, contida na obra Elementos para a leitura dos textos filosóficos (COSSUTTA, 1994), relacionada com a busca de exercícios para a interpretação e compreensão de textos filosóficos, apresentamos uma possibilidade de exercício:

1) Relendo o texto constante no último parágrafo da página 114 da obra As viagens de Gulliver, continuado na página 115, transcrito abaixo, retire e exponha problemática(s) apresentada(s) no referido parágrafo.

Nesta terrivel agitação, não podia deixar de pensar no país de Lilipute, cujos habitantes me haviam considerado como o maior prodígio que até então aparecera no mundo, onde era capaz de arrastar só com uma das mãos toda uma esquadra e de praticar outras ações maravilhosas, cuja memória será eternamente conservada nas crônicas daquele império, embora a posteridade não queira acreditar, ainda que confirmadas por uma nação inteira. Refleti que mortificação não seria para mim parecer tão miserável aos olhos da nação, onde agora me encontrava, como o seria um liliputiano entre nós; no 
entanto, olhava isto como a menos das minhas fatalidades, porque é coisa para notar que os entes humanos são ordinariamente mais selvagens e mais cruéis em proporção ao seu tamanho e, assim refletindo, que podia eu esperar senão ser um manjar na boca do primeiro daqueles enormes bárbaros que me apanhasse? De fato, os filósofos têm razão, quando dizem que não há grande nem pequeno senão por comparação. Talvez os liliputianos encontrassem alguma nação menor em relação a eles, como me pareceram, e quem sabe se esta prodigiosa raça de mortais não seria uma nação liliputiana em relação à de qualquer outro país, que não descobrimos ainda? Mas, aterrado e confuso, não fiz então todas estas observações filosóficas. (SWIFT, 1950, p.114-115)

2) Reflita acerca das possibilidades de verdades apresentadas no parágrafo supracitado, relacionando ao sentido de verdade que é abordada por René Descartes, ou ainda Edmund Husserl. Tendo a noção que, sucintamente, ambos os filósofos têm a seguinte percepção de verdade:

René Descartes - Em seu processo investigativo em relação a verdade, Descartes cria que o ser humano se insere em diversificados níveis culturais, da mesma forma que as diversas comunidades científicas. Desta forma, por sua especificidade, estão conectadas a um paradigma específico, comprometendo sua visão de mundo relacionada a realidade encontrada na natureza. De maneira que conceitos, imagens, metáforas, emoções, etc, são mera interpretação, de maneira particular, sobre o fato.

Edmund Husserl - Husserl apresenta que a verdade se dá através da fenomenologia, ou seja, através de fenômenos perceptíveis, observáveis, e sensíveis. A verdade são atos significativos e intuitivos que se correspondem. Só terá percepção de verdade através das vivências obtidas.

O exercício anteriormente proposto serve apenas como exemplo cossuttariano do que se pode abordar tendo em vista a obra de Jonathan Swift. Ainda se pode, após a análise do trecho proposto, em surgindo outras problemáticas, que se relacione com o pensamento de outros filósofos, ou ainda, mesmo no exercício acima, que se parametrize com outros pensamentos diversos aos dois filósofos apontados.

Ainda, se percebe que a atenção ao escrito deve ser matéria premente ao se realizar a leitura de literatura "não filosófica" com sentido filosófico, pois a significação da ideia decorre do contexto empreendido pelo autor, bem como da interpretação e análise do leitor/filósofo. Conforme Cossutta:

O fato de que o filósofo deva incessantemente prestar atenção ao sentido vai levá-lo a formular observações sobre a língua em geral, sobre o estatuto filosófico da significação, de tal modo que ele será levado a elucidar filosoficamente seu próprio uso da linguagem [...] (COSSUTTA, 1994, p. 45).

O texto nos apresenta o reino de Lilipute com elevado senso moral acerca de regras e normas, as punições aos improbos e criminosos são, deveras, elevadas, isto tudo com uma única finalidade e justificativa de "manter a ordem". Entretanto, mesmo com a rigidez da legislação, a corrupção é visível e também bastante elevada naquele reino, haja vista que o escrito nos apre- 
senta a situação do pai do atual Imperador onde, certa feita, introduz um modelo de escolha de agentes públicos que se apresenta pouco convencional. Nesta parte percebemos que se deve fazer uma pausa e pensarmos em nosso atual contexto político e econômico no Brasil, acaso tal situação continua ocorrendo? Destacamos, mais uma vez, a atemporalidade do texto.

Várias anotações trazidas pelo autor nos coloca uma problematização. É interessante a existência de uma frase no texto que chama muito a atenção: "não há grande nem pequeno senão por comparação" (SWIFT, 1950, p.115). O que podemos perceber com tal frase? Ele nos apresenta que - na visita de Gulliver a Lilipute e Blefuscu, onde ele era considerado gigante; depois em sua visita a Brobdingnag, onde ele era muito pequeno - os diversos pontos de vista da realidade sensível que devem ser tomados em consideração, são pontos de vista diferentes, diversos e divergentes, onde nos revelam diferenças em relação às mesmas coisas. Aqui percebemos que todos os pontos de vista devem ser considerados e debatidos, com suas virtudes e deficiências, mas sem excluí-los jamais, sem fechar-se em um discurso ou uma ideia abstrata, mesmo que aparentemente sejam divergentes ao que consideramos como correto e verdadeiro enquanto professores. Muito bem Cossutta trata deste fator.

[...] mas o filósofo não se fecha dentro de um discurso totalmente abstrato. A dimensão referencial é uma dimensão essencial que permite escapar de uma dicotomia entre um "mundo das abstrações" e um "mundo das realidades". [...] O objeto concreto, que pode ser atestado pela experiência, é apenas uma forma particular dele, uma vez que uma das tarefas da filosofia consiste em visar idealidades. (COSSUTTA, 1994, p.73).

É interessante o ponto de vista que nos sugere que Gulliver, o personagem principal desta aventura, sempre é tomado como alguém próximo, até mesmo sendo considerado quase que um integrante da família a qual o toma, porém, ao final, sempre é usado de forma a parecer objeto, seja ele maior, seja menor, seja diferente. Isto nos remete à crueldade do ser humano, onde é capaz do uso de seu semelhante para benefício próprio, descartando-o assim que não mais seja necessário.

Neste ínterim podemos considerar o pensamento kantiano relacionado à ética. Kant processa o ato de sempre ver no outro um fim em si mesmo, donde, para ele, a dignidade humana consiste em fazer o que é correto. Entretanto este "fazer o que é correto" relaciona-se a fazer sem preocupar-se com consequência, pois seu valor não consiste nisso, mas sim na intenção que fora depositada para tal ação. O importante é fazer o correto pelo simples fato de ser o correto. A boa vontade conduz a ação boa, onde será capaz de criar uma norma universal garantidora da boa ação. Não basta apenas que a ação se enquadre na lei moral, é necessário que ela deve ser praticada em prol da lei moral.

Para Kant, existe diferença entre fazer um ato de ajuda a outrem por prazer e por dever, nisto, a ação por prazer não entra no rol da moralidade. Portanto o altruísmo, apesar de ser algo correto e cordial, não possui valor moral. Aparentemente temos um contrassenso aqui, entretanto, para Kant, o homem não pode ajudar outros por prazer, pelo fato de the fazer bem, mas sim deve ajudar pelo dever de ajudar. Tais situações aqui estão citadas para exemplificar a forma a serem explorados alguns conceitos que podemos observar com a obra destacada para este trabalho, pois percebemos o conceito da ética em diversos momentos no texto.

Em outra de suas viagens, agora à Brobdingnag, Gulliver é questionado pelo Rei local acerca da vida em sua terra. Nos questionamentos do Rei se percebe a contrariedade deste em relação ao governo essencialmente patrimonialista do povo apresentado por Gulliver, a Inglaterra, onde o bem público se confunde com o bem particular. Aqui percebemos novamente o contexto ético 
e político a que o autor traça o texto. Após as objeções do Rei (diga-se de passagem, gigante aos olhos de Gulliver, ou seja, fala com "superioridade" em relação ao interlocutor) e respostas de Gulliver, o Rei prova para si e para o amigo que, de fato, estava certo em relação ao povo de Gulliver.

Outro fato interessante na obra é que ao deixar a Lapúcia e ir a Balnibarbos, Gulliver se defronta com pensamentos completamente diferentes. Na Lapúcia os habitantes são "avoados", não possuem iniciativa para fazer determinadas coisas, enquanto que em Balnibarbos, ao visitar a academia, ele se nota rodeado de pessoas que sempre estão em busca de algo, inquietos, porém fechados em suas certezas, envoltos por uma casca de suas aspirações, porém essa casca é deveras fina e quebradiça, ao passo que pode facilmente ser desmantelada e tal certeza ser falseada. Aqui percebemos até um nível de racionalismo crítico, mesmo tendo o texto sido escrito anterior ao pensamento de Popper. O autor nos traz a ideia de que o mundo é exatamente desta forma, cheio de certezas envoltas em cascas quebradiças.

A viagem de Gulliver ao país de Huyhnhnms apresenta seres que se parecem com cavalos e que consideram os humanos como animais. Ou seja, um tipo de animal racional que percebe a raça humana como irracional, os papéis se invertem, é neste lugar que Gulliver deseja permanecer (com uma pitada de ironia do autor), porém não o é aconselhado tal por conta da decisão de extermínio dos "yahus", humanos considerados irracionais, aos quais muito o povo de Gulliver se parece.

A imagem deturpada da humanidade é o ponto principal desta viagem e o aspecto totalitário do povo visitado chama a atenção. Neste caso, como mero exemplo e com a consciência de que tal fato não é o único ato de maldade que existiu no mundo, ainda hoje pode-se presenciar atrocidades com menos favorecidos, poderia se fazer um paralelo entre aquele povo e os nazistas, tendo os "yahus" como fossem os judeus. Por conta desta visão deturpada da humanidade, Gulliver não consegue mais apreciar as virtudes dos indivíduos de sua espécie.

Nas diversas exemplificações que Swift propõe onde apresenta críticas veladas ao seu próprio contexto político e social, podemos perceber que pode ser gerada certa confusão na leitura do texto, especialmente por aqui estarmos tratando de jovens e adolescentes que podem ainda não possuir senso crítico de tal forma que os levem à percepção do contexto velado, mesmo que o vocabulário apresentado não seja de tamanho grau dificultoso como o são determinadas obras de gênero filosófico. Referente a isso, Cossutta nos explica que:

O filósofo constrói um universo definido e ordenado de palavras e de frase que desnorteia o leitor e provoca um sentimento de incompreensão por perda de orientação, de inteligibilidade. Sentimo-nos perdidos porque os termos conservam para nós resíduos de significação mais ou menos confusos, que é preciso afastar em proveito de uma atribuição precisa do sentido. (COSSUTTA, 1994, p.60).

Existem muitas outras problematizações que podem ser verificadas no texto, que é muito rico em relação a isso, além das observações já apresentadas neste estudo. No mesmo sentido se faz importante o friso acerca da percepção de que o autor se utiliza de metáforas para explicar a realidade em que o mesmo se encontra. Neste ínterim percebemos que a filosofia muito se utiliza desta ferramenta de linguagem, assim como nos aponta Derrida:

A avaliação filosófica sempre foi ambígua: a metáfora é ameaçadora e estranha ao olhar da "intuição" (visão ou contato), do "conceito" (captura ou presença própria do significado), da "consciência" 
(proximidade da presença em si). Mas ela é cúmplice do que ameaça, ela lhe é necessária na medida em que o [dé tour] é um retorno [re-tour] guiado pela função de semelhança (mimesis e homoiosis) sob a lei do mesmo. A oposição da intuição, do conceito, da consciência já não tem pertinência alguma. Esses três valores pertencem à ordem e ao movimento do sentido. (DERRIDA, 1988, apud COSSUTTA, 1994, p.101).

\section{SENSIBILIZAÇÃO EM SALA DE AULA}

Como sensibilização para uma aula de filosofia no sentido proposto pelo presente trabalho, poderia ser utilizada a obra As Viagens de Gulliver justamente para verificar este contexto histórico, ético e político, que, como outrora acontecera com diversos jovens e adolescentes, são assuntos intrínsecos que passam despercebidos da maioria dos estudantes do Ensino Médio. Para tanto, se deve fazer um convite à dúvida, da maneira exposta por Ramos, Gutierres e Kich:

Nesse convite à dúvida e ao pensamento epistemológico, que busca superar o conhecimento comum e questionar a realidade, reside um dos aspectos primordiais de concatenação entre os estudos de filosofia e de literatura. Assim como a filosofia, a literatura também pode atuar na formação do sujeito. [...] A literatura se constitui organicamente na civilização, à medida que os elementos nela presentes, de natureza psíquica e social, se manifestam historicamente através do texto ficcional. (RAMOS, GUTIERRES, KICH, 2011, p.318).

Este contexto ainda hoje vige, haja vista a sua atemporalidade como antes mencionada. Poder-se-ia apresentá-lo lançando o desafio de averiguação se a questão ético/política ainda está em destaque da mesma maneira que se verifica na época de Swiftę Que diferenças e/ou semelhanças percebemos com esta questão atualmente? Ainda, por qual motivo Swift se utiliza desta fantasiosa imaginação em seu escrito? O que ele pretendia denunciar ou apurar? A questão do ponto de vista (gigante x minúsculo) o que tem a nos dizer atualmente? Enfim, diversos questionamentos são possíveis com esta bela obra, pois, no dizer de Ramos, Gutierres e Kich: "Tanto a literatura quanto a filosofia retratam problemáticas do contexto social e histórico das sociedades de época em que os textos foram escritos." (RAMOS, GUTIERRES, KICH, 2011, p.322).

Neste ponto destaca-se o pensamento do francês Gilles Deleuze ao relacionarmos a situação anteriormente proposta ao seu conceito de diferença e repetição. Deleuze coloca que a diferença é a principal forma da dinâmica, ou seja, é algo plenamente mutatório, busca apresentar nova forma de olhar as diversas perspectivas propostas às testemunhas. Para ele a filosofia é a atividade da criação de conceitos, questão importante quando o trabalho realizado refere-se à abordagem filosófica de textos "não filosóficos". Por isso, as diferenças físicas e intelectuais propostas no texto podem passar pelo crivo do leitor visando sua contextualização filosófica.

Deve-se buscar influenciá-los (os alunos) para a reflexão à leitura da obra, não apenas lê-la, mas também meditá-la e extrair daí o cerne do escrito, retirar os pontos a que o autor queira chegar. Por tudo isso se torna obrigatório o conhecimento mínimo do contexto histórico, bem como elementos filosóficos oriundos do texto, para melhor compreender esta fantasiosa obra literária e, porque não dizer, filosófica? Ainda que o intento deste trabalho seja a utilização de obras literárias enquanto recurso ao estudo da filosofia. Portanto deve-se influenciar na aproximação entre filosofia e literatura com a finalidade de tornar o trabalho rico em abstrações. 
Permitir, no âmbito escolar, uma aproximação entre filosofia e literatura enriquece o trabalho a ser desenvolvido em sala de aula. Proporcionar ao aluno a leitura de um clássico, possibilitando-lhe questionamentos que agregam conhecimento para sua vida, é uma forma de colaborar para seu crescimento pessoal e intelectual. (RAMOS, GUTIERRES, KICH, 2011, p.322).

Essa aproximação entre a filosofia e a literatura pode transformar a sala de aula em uma verdadeira comunidade de investigação ${ }^{3}$, porém temos de ter em vista que aqui nos dirigimos a alunos do ensino médio e que ainda possuem contato restrito com a filosofia. Tal fator se torna possível pois os alunos e alunas passam a identificar-se com o desenvolvimento do trabalho enquanto grupo, diferentemente de fixar-se nos pontos de vista particular. Poderão, cooperativamente, construir significados relacionados aos conceitos filosóficos e problemáticos retirados do texto, tornando a investigação de maneira coletiva.

Enquanto uma comunidade de investigação filosófica, o grupo de alunos é possibilitado à experiência da vivência de um contexto de diálogo e cooperação, sem quaisquer traços de manipulação, quer seja por parte do professor, quer seja por parte do aluno. Este fato acaba por permitir a tolerância relacionada a perspectivas distintas, oriundas na personalidade e interpretação de cada integrante do grupo, ou seja, de cada aluno.

Tal metodologia oferece aos alunos, participantes desta comunidade de investigação, um aprofundamento experiencial de maneira epistemológica e democrática. Em determinado momento os integrantes desta comunidade poderão perceber as novas possibilidades advindas de tal experiência através da sensibilização com o outro, conectados às ideias oriundas da leitura e interpretação do texto. Tal fato se potencializa tendo em vista que aqui abordamos textos literários clássicos, que, dentre outras características, possui um conceito fantasioso e aventureiro.

Neste sentido, tendo por base a obra na qual nos debruçamos neste trabalho, a comunidade de investigação filosófica proposta oferece aos alunos a possibilidade de tornar-se consciente às praticas de habilidades cognitivas, bem como abordar em grupo as suas conclusões, criar valores. Apresenta uma oportunidade de um ambiente adequado para o crescimento cognitivo, político, ético, etc. Neste contexto podemos perceber que a comunidade de investigação será capaz de vivenciar o diálogo, bem como a comunicação entre os pares. Tal fator torna-se imprescindível quando o relacionamos com a confiança e o compromisso de cada aluno e aluna em sala de aula.

O texto proposto para o presente trabalho torna-se favorável para uma comunidade de investigação filosófica ${ }^{3}$, haja vista que pode ser considerado agradável e problematizador, literário e filosófico - quando bem orientado - e com uma clara proposta, pois cada qual poderá exercitar o seu poder de abstração, mas também de corporificação, de compreensão e de interpretação, trazendo o entendimento próprio acerca da intenção de Swift ao escrever tal obra extraindo dela conceitos e problematizações filosóficas. Mesmo que a filosofia, no nosso caso, esteja implícita no texto, devendo ser extraída, o que, deveras, se torna importante trabalho a ser realizado. Neste sentido a interdisciplinaridade se mostra favorável, pois, como bem apresentam Ramos, Gutierres e Kich, não é pela natureza disciplinar de determinado texto que podemos considerá-lo filosófico.

$\overline{3 \text { Comunidade }}$ de investigação é um conceito criado pelo filósofo estadunidense Mattew Lipman. A investigação enquanto comunidade surge como prática de investigação de forma a desenvolver competências e habilidades dos participantes em um processo dialógico provocado em sala de aula a partir de situações surgidas visando influenciar a pesquisa filosófica nos alunos. Ainda, Ann Sharp, colaboradora de Mattew Lipman, propõe ênfase na relação da criança com a comunidade de investigação, colocando que a investigação ocorre onde os alunos possam começar a pensar de maneira diferente, levados a compreender o que se expõe, onde o principal instrumento sempre é o diálogo. 
Nesse sentido é preciso ressaltar que cabe ao professor colocar o aluno em contato com diferentes modalidades discursivas [...] que faz da leitura de um texto uma atividade filosófica não é a natureza disciplinar do texto lido, mas o modo como o leitor lê este texto; ou seja, o essencial dessa atividade está no modus operandi do leitor face às diferentes formas de enunciação. (FABBRINI, 2005, p.8).

O texto, apesar de tecnicamente apresentar termos pouco convencionais atualmente, não se utilizando propriamente de linguagem filosófica, no dizer de Granger onde explicita que "Não há, propriamente falando, língua filosófica, mas apenas um uso filosófico da língua" (GRANGER, 1988, apud COSSUTTA, 1994, p.40), é agradável a ponto de tornar mais aprazível sua leitura para os alunos do Ensino Médio, diferentemente dos textos filosóficos mais importantes que muitas vezes são de difícil compreensão para a idade média destes alunos.

\section{CONSIDERAÇÕES FINAIS}

Ao findar a presente reflexão acerca da utilização de clássicos literários nas aulas de filosofia, aqui utilizando, como exemplo de possibilidade, a obra As Viagens de Gulliver, de Jonathan Swift, podemos perceber quão rica pode ser a união entre filosofia e literatura que, ambas, dialogando de forma interdisciplinar, pode possibilitar ao aluno do ensino médio a formação de problematizações chegando a conceitos que podem ser interpretados ao perceber a relação que o texto possibilita parametrizando-a com a realidade vivida e presenciada por cada aluno.

Além da interdisciplinaridade contida ao analisarmos textos literários com a filosofia podemos perceber que ainda conseguimos chegar a questões ligadas a historicidade, bem como, sociologicamente. Desta forma podendo abranger diversas áreas de estudo com o intuito de formar alunos como pessoas questionadoras e observadoras capazes de interpretar e compreender. Esta interação entre áreas de conhecimento abre excelente espaço para a investigação, tornando a sala de aula uma comunidade investigativa. Tendo em vista tal situação percebemos que, para tal, se deve construir e reconstruir a essência do texto a ser estudado, mesmo que os elementos filosóficos que estruturam o texto aparentemente estejam ocultos.

O estudo filosófico a partir de obras literárias clássicas, tendo em vista a idade dos alunos do ensino médio, pode tornar mais agradável o estudo da filosofia, pois obras da envergadura e gênero da obra ora exemplificada trás entusiasmo aos alunos, especialmente por conta de sua redação aventureira e fantasiosa, gerando grande interesse do jovem leitor/filósofo.

O aluno pode perceber que questões abordadas há longo tempo ainda persistem e continuam a gerar intriga ao serem analisados. Questões relacionadas à ética e moral, à política e convivência, são amplamente abordadas nesta obra concebendo diversas problematizações que podem ser abordadas.

Possibilitar ao aluno que possa efetuar uma leitura atenta de obras literárias clássicas é deveras importante tendo em vista o contexto em que esses se encontram, onde o imediatismo toma conta e a leitura efetiva e eficaz se torna cada vez mais insólita, impossibilitando que os mesmos se tornem atores de uma sociedade crítica e questionadora. Importante ressaltar que a leitura atenta apenas não basta, é importante ultrapassar suas habilidades cognitivas, detendo-se, também, em suas habilidades conceituais. Neste contexto a filosofia pode ser o ponto divergente do senso comum cada vez mais habitual. Portanto podemos tornar as aulas filosóficas cada vez mais interessantes para podermos possibilitar a ampla participação desta pequena comunidade de investigação que é a sala de aula, devendo o professor não colocar-se em um palco, mas sim estar em um tablado, desconsiderar-se como "mestre", mas sim um mediador das ideias oriundas dos alunos desta comunidade. 


\section{REFERÊNCIAS:}

COSSUTTA, Frédéric. Elementos para a leitura dos textos filosóficos. Trad. Angela Noronha Begnami et al. São Paulo: Martins Fontes, 1994.

FABBRINI, Ricardo Nascimento. O ensino de filosofia: a leitura e o acontecimento. Trans/Form/Ação, São Paulo, v. 28, n. 1, p. 7-27, 2005. Disponível em: http://www.scielo.br/pdf/trans/v28n1/29404.pdf . Acesso em 08 mai. 2018.

RAMOS, Flávia Brocchetto; GUTIERRES, Athany; KICH, Morgana. Filosofia e literatura: diálogo motivado a partir de Platão e Tchekhov. Educação, Porto Alegre, v. 34, n. 3, p. 317-323, set./ dez. 2011. Disponível em: http://revistaseletronicas.pucrs.br/ojs/index.php/faced/article/ view/8192/6781. Acesso em: 05 mai. 2018.

SWIFT, Jonathan. As viagens de Gulliver. Trad. Cruz Teixeira. Clássicos Jackson, v. 31, 1950. E-book disponível em: http://www.ebooksbrasil.org/adobeebook/gulliver. pdf . 